\title{
Global Efforts towards Potential Therapeutic Options for COVID-19
}

\author{
Pooja Prajapati ${ }^{1}$, Rekha Kumar ${ }^{2}$, Santosh Kumar Prajapti ${ }^{3 *}$ \\ ${ }^{1}$ Satguru Partap Singh Apollo Hospitals, Ludhiana, Punjab-141001, India \\ ${ }^{2}$ Govt. Homoeopathic Medical Collage and Hospital, Bhopal, Madhya Pradesh-462003, India \\ ${ }^{3}$ Department of Medicinal Chemistry, Columbia Institute of Pharmacy, Raipur, Chhattisgarh-493111, India
}

${ }^{*}$ Corresponding author: Santosh Kumar Prajapti, Assistant Professor, Department of Medicinal Chemistry, Columbia Institute of Pharmacy, Raipur, Chhattisgarh 493111 India, Tel: +916300866515; E-mail: santoshnavodaya2003@gmail.com

Received date: Apr 16, 2020; Accepted date: Jun 06, 2020; Published date: Jun 12, 2020

Citation: Pooja P, Kumar R, Santosh Kumar P (2020) Global Efforts towards Potential Therapeutic Options for COVID-19. Arch Med Vol. 12 Iss. 3:13

Copyright: (C2020 Pooja P, et al. This is an open-access article distributed under the terms of the Creative Commons Attribution License, which permits unrestricted use, distribution, and reproduction in any medium, provided the original author and source are credited.

\section{Abstract}

An epidemic spread of novel coronavirus (COVID-19) infection has posed significant threats to global public health and the economy. Scientists around the world are endeavoring to find potential antiviral effective in combating COVID-19. Currently, there is no specific treatment for COVID-19, however several drugs are currently under clinical investigation to test their efficacy and safety during the treatment of coronavirus disease 2019 (COVID-19). Based on published evidence, we have summarized the present therapeutic agents effective against SARS-CoV-2.

Keywords: COVID-19; Coronavirus; 2019-CoV; Therapeutic options

\section{Introduction}

In December 2019, the epidemic of severe acute respiratory syndrome coronavirus 2 (SARS-CoV-2), emerged from Wuhan, China and have now spread worldwide because of its probable high transmission efficiency [1]. It has become public health emergency of international concern and has received much attention from health organizations worldwide. The respiratory infection induced by the SARS-CoV-2 (formerly 2019-nCoV), is named coronavirus disease 2019 (COVID-19), is responsible for the mortality rate estimated about $6 \%-7 \%$, increasing with age and the existence of underlying diseases. As per WHO updates on June 04, 2020, this virus has affected more than 6,287,771 people worldwide and caused more than 379,941 deaths, the majority of them occurring in Europe [2]. COVID-19 is now becoming pandemic due to lack of or specific anti-viral drug regime to treat infected patients, although many are in rapid development and some may be available in a short time [3-6]. The management of patients is mainly focused on supportive care, such as oxygen supply and extracorporeal membrane oxygenation and fluid management [7].

\section{Literature Review}

\section{Potential therapeutic options for COVID-19}

The scientists and doctors are desperate to find ways to control the spread of the novel coronavirus and to find effective treatments. Till date, a number of clinical trials are under investigation to find specific treatment or vaccines against COVID $19[7,8]$. New ones are being added to accelerate the progress of drug development, as the case counts are exponentially increasing worldwide. The drugs from repurposed flu treatments to failed ebola drugs and malaria treatments are being tested, which have been developed long ago $[9,10]$. Herein, the article deals with the current therapeutic agents with potential efficacy against SARS-CoV-2.

\section{Antiviral therapy}

The antiviral drug Kaletra, a combination of lopinavir and ritonavir, generated early excitement for the treatment of COVID-19 patients [11]. The drug manufactured by AbbVie laboratories to inhibit HIV protease enzyme which cleaves a peptide chain during assembly process of viruses [12]. This combination has also been tested in patients with MERS and SARS though those results are ambiguous $[13,14]$. In addition, the first trial for the treatment of COVID-19 patients using lopinavir and ritonavir was not found to be promising in 199 patients of China [15]. Nevertheless, other studies are still ongoing, and there's still a possibility of this drug show some benefit, if administered with interferons, which reduce viral load in the early stage of viral infection and can help to alleviate symptoms and shorten the course of disease. Although interferons might be risky for patients with severe COVID-19, if it is given late and it may lead to aggravate the tissue damage [16]. Furthermore, many clinical trials of Kaletra 
are underway with various combinations of guanosine-analog RNA synthesis inhibitors, reverse transcriptase inhibitors or influenza drugs, such as baloxavir marboxil, oseltamivir. The drugs targeted RNA synthesis inhibitor such as rivavirin and reverse transcriptase inhibitors (emtricitabine/tenofovir alafenamide fumarate) are also being tested in combination with Kaltera, since the replication machinery of other viruses similar to those in SARS-CoV-2 [17].

Remdesivir (GS-5734), a novel nucleotide analogue developed by Gilead is an experimental broad-spectrum antiviral originally intended for treatment of Ebola virus infection. However, the drug was not found to be effective against Ebola virus, but in some studies, it has proven to be efficient against severe acute respiratory syndrome coronavirus 2 (SARS-CoV-2) in vitro and related coronaviruses (including SARS and MERS-CoV) both in vitro and in vivo $[10,18-20]$. The compassionate use (a patient with severe COVID-19 disease can be approved for treatment) of remdesivir through an investigational new drug application was described in a case report of one of the first patients with COVID-19 in the United States [21]. Although, this drug is still under clinical tests and has yet to be approved, before being considered as an effective and official drug to treat COVID-19 patient. Remdesivir (GS-5734) is a prodrug, where the phosphoramide gets cleaved off completely and transformed in to active 5-OH compound GS-44-1524. Its mode of action is to get incorporated into viral RNA, since it's taken up by RNA polymerase and seems to evade proofreading and thus viral replication is inhibited [22].

As the COVID-19 cases continue to rise globally, the antiviral drug Favipiravir, has been used in Japan to treat influenza, which is currently being promoted with the label, Avigan, has become the first-ever antiviral medicine to be approved for the treatment for COVID-19 in China. The National Medical Products Administration of China has approved Favipiravir to stop the widespread of this fatal illness after it appeared to be effective in COVID-19 patients during clinical studies. Favipiravir, which has proven to be an effective antiviral drug for fighting viral infections by inhibiting the RNA-dependent RNA polymerase, is mainly used for treating influenza. As per medical authorities in China, Favipiravir has been tested in 340 individuals in Wuhan and Shenzhen, which displayed promising outcomes in clinical trials of 340 COVID-19 patients in aspect of high degree of safety and effective treatment $[23,24]$. In addition, a randomized clinical trial for Favipiravir versus Arbidol was also studies for COVID-19 where favipiravir was found to be better candidate as compared to arbidol due to superior clinical recovery rate and more effective in fever reduction and cough relief [25].

\section{Antimalarial drugs therapy}

Chloroquine and hydroxychloroquine (FDA approved antimalarial and autoimmune disease drugs) have received significance due to potential antiviral activity in recent studies $[20,26,27]$. Scientists anticipated the possibilities of chloroquine and hydroxychloroquine as potential drug for the treatment of COVID-19 on the basis of earlier literature reports
[28-30]. where related SARS-CoV virus could be prevented by chloroquine. Chloroquine is known to block virus infection by increasing endosomal $\mathrm{pH}$, making the cell compartment more basic environment which is not suitable for the SARS-CoV virus to replicate, as well as it also prevent SARS-CoV from plugging into a receptor called angiotensin-converting enzyme 2 (ACE2) on primate cells [28].

In February 2020, Wang and coworkers established the effectiveness of chloroquine against SARS-CoV-2 infection in vero E6 cells [20]. Later on, in vitro studies of closely related drug hydroxychloroquine (a less toxic derivative of chloroquine) also showed considerable inhibition of SARSCoV-2 replication [31].

Preliminary reports from China who treated more than 100 patients have demonstrated that chloroquine phosphate is superior to the control treatment in inhibiting the pneumonia caused by COVID-19 [26]. Furthermore, Raoult and coworkers reported a study of hydroxychloroquine alone or in combination with an antibiotic called azithromycin in twenty COVID-19 patients, displayed significant reduction of SARSCoV-2 concentration and it work even better with the antibiotic azithromycin [32]. Due to higher in-vitro activity against SARS-CoV-2 and its wider human safety, hydroxychloroquine has been administered to hospitalize COVID-19 patients globally.

According to the Centers for Disease Control and Prevention (CDC), Both drugs are generally well tolerated at prescribed doses for COVID-19 patients, with the main concerns that the medication interact with other drugs and doses should be adjusted to account for drug interactions. These drugs are not safe for patient with heart arrhythmia, hepatic/renal dysfunction and immunosuppression. Assuming the drugs are well tolerated in clinical trials and seem effective at treating COVID-19, the FDA will take measures to increase the nation's supply [33].

\section{Corticosteroid therapy}

SARS management related researchers are also involved in corticosteroid therapy for the treatment of COVID-19 patients. However, WHO and CDC do not recommend the patients with COVID-19 pneumonia unless there is exacerbation of chronic obstructive pulmonary disease[34,35]. Glucocorticoids have been associated with an increased risk for mortality in patients with influenza and delayed viral clearance in patients with MERS-CoV infection. Although they were widely used in management of SARS, there was no good evidence for benefit, and there was persuasive evidence of adverse short- and longterm harm [36].

\section{Rheumatoid arthritis drugs}

Baricitinib, a licenced drug for the treatment of rheumatoid arthritis was found to be capable to reduce or interrupt the entry of the virus into target cells via inhibiting the Janus kinase-1 (JAK1) and Janus kinase-2 (JAK2) mediated cytokine release. The promising results of baricitinib on viral entry and cytokine outbreak constituted the rationale to perform a trial 
on the patients with mild to moderate COVID-19 receiving antiviral therapy, since it does not interact with antivirals due to its prevalent renal elimination [37].

Tocilizumab is an approved monoclonal antibody to treat rheumatoid arthritis via blocking the IL- 6 signalling pathway. Currently, there is limited evidence on the safety or efficacy of the drug in clinical treatment of covid-19; however it is under investigation by the FDA through a double blind, randomised phase III clinical trial to treat covid-19 patients [38].

\section{Angiotensin-converting enzyme 2 (ACE2) inhibitors}

Other approved and experimental treatment is to block cellular entry of virus via angiotensin-converting enzyme 2 (ACE2) and the cellular protease transmembrane protease serine 2 (TMPRSS2) present in spike glycoprotein of SARSCoV-2. So, some researchers have hope for camostat mesylate, a marketed drug for pancreatitis, which inhibits TMPRSS2 involved in infection [39].

Some of the researchers also raised the possibilities of antihypertensive drugs particularly ACE inhibitors/angiotensin II receptor blockers (ARBs) to prevent COVID-19, since SARSCoV-2 binds to the angiotensin-converting enzyme 2 (ACE2) receptors for infecting the cells [40]. However, recent paper published in March 2020 suggested that the ACE inhibitors might actually prompt the body to make more ACE2, thereby increasing the ability of the virus to penetrate cells. Thus, the ACE2-stimulating drugs used in the treatment of diabetes and hypertension may increases the risk of developing severe and fatal COVID-19[41,42]. Therefore, clinical studies are required to explore COVID-19 susceptibility and corresponding treatment strategies in patient treated with ACE ACE2stimulating drugs.

APN01 is a recombinant human Angiotensin Converting Enzyme 2 (rhACE2), developed by APEIRON biologics received regulatory approvals in Austria, Germany and Denmark to start a Phase II clinical trial on COVID-19 patients. It is a recombinant form of the human angiotensin-converting enzyme 2 (rhACE2), and has the potential to stop the SARSCoV-2 virus infection followed by reduction of harmful inflammatory reactions inside the lungs. The Phase II trial aims to treat 200 severely infected COVID-19 patients and expected to be initiated shortly [43].

\section{Non-steroidal anti-inflammatory drugs (NSAID)}

Some researchers and clinicians suggested the use of nonsteroidal anti-inflammatory drugs (NSAIDs) such as ibuprofen early in the course of disease may have risk of severe adverse effects whereas acetaminophen can be recommended in lowest effective dose [44]. However, there is no clinical or population-based data that NSAIDs are dangerous for patients with COVID-19. But there are possibilities of GI bleeding, fluid retention, and renal dysfunction in critically ill patients.

\section{Convalescent plasma (CP) therapy}

Convalescent plasma therapy is also under investigation to treat patients with severe or life-threatening COVID-19. Recently, convalescent plasma containing neutralizing antibody was studied on 5 critically ill patients with COVID-19 and acute respiratory distress syndrome (ARDS). The preliminary findings increase the possibility of convalescent plasma transfusion as potential treatment of critically ill patients with COVID-19 and ARDS, however this approach requires assessment in randomized clinical trials [45]. Furthermore, Duan et al. reported the convalescent plasma therapy on ten severe COVID-19 patients with one dose $(200 \mathrm{~mL})$ of convalescent plasma. Significantly, it was well tolerated and could maintain the neutralizing antibodies at a high level, leading to disappearance of viremia in 7 days. However, the clinical symptoms of severe COVID-19 patients were found to be improved within 3 days of the treatment [46].

\section{Coronavirus vaccines}

In a very recent report, researchers have demonstrated a potential vaccine against SARS-CoV-2, which has shown to be promising in early testing of mice for the production of antibodies against SARS-CoV-2. The vaccine is delivered through a fingertip-sized patch of 400 small needles called microneedle array approach. The patch is placed like a bandage and the needles, made of protein pieces and sugar which dissolve into the skin [47].

The public health emergencies caused by SARS-CoV-2, clearly demonstrate the necessity to evaluate candidate vaccines to combat these outbreaks. Continuous efforts from investigators to quickly develop safe vaccines against these emerging infections are challenging task. As par recent article published by Le et al., the five vaccine candidates including mRNA-1273 from Moderna, Ad5-nCoV from CanSino Biologicals, INO-4800 from Inovio, LV-SMENPDC and pathogen-specific aAPC from Shenzhen Geno-Immune Medical Institute have recently moved into phase 1 clinical trials [48].

\section{Miscellaneous}

In the race to find effective treatment for COVID-19 by utilizing repurposed drugs, Wagstaff and coworkers reported the potent antiviral activity of ivermectin (an FDA-approved anti-parasitic drug) towards SARS-CoV-2 infected Vero/hSLAM cells. In this study, the viral colonies was shown to be reduced by $\sim 5000$-fold within 48 hours of a single treatment in a cell culture infected in a laboratory. However, further investigation for possible benefits in humans is still required [49].

According to Sheahan et al. studies on treatment of viral infection, a ribonucleoside analog $\beta$-D-N4-hydroxycytidine (NHC, EIDD-1931) has displayed broad spectrum antiviral activity against SARS-CoV-2, MERS-CoV, SARS-CoV in mice. In addition, the compound has sown promising results on BatCoVs and coronavirus resistant to the remdesivir. Clinical studies of EIDD-2801 in humans are expected to begin soon. 
The drug would be beneficial not only to limit the spread of SARS-CoV-2, but also control future outbreaks of other emerging coronaviruse, if successful in clinical trials on human beings [50].

\section{Conclusion}

As the recent outbreak of COVID19, scientists around the world are actively involved in rapid identification of effective therapeutic agents that would be potentially effective in combating COVID-19. Most of therapeutic options are based on the past experience of treating SARS, MERS or other viral infections. So far, there are no specific antiviral drugs/vaccines for COVID19, however several existing drugs including chloroquine, hydroxychloroquine remdesivir, favipiravir, lopinavir/ritonavir combined with interferons, convalescent plasma monoclonal antibodies etc. were shown to be effective against 2019-nCoV. But, the safety and efficacy of these drugs for COVID-19 patients need to be assessed by further clinical trials.

\section{Declaration of Competing Interest}

The author declared no competing interests.

\section{Acknowledgement}

The authors would like thank to Prof. K. P. R. Kartha for his kind support in writing of the manuscript.

\section{References}

1. Huang C, Wang Y, Li X, Lili R, Zhao J, et al. (2020) Clinical features of patients infected with 2019 novel coronavirus in Wuhan, China. Lancet. 395:497-506.

2. https: //covid19.who.int/

3. Wu Z, McGoogan JM (2020) Characteristics of and important lessons from the coronavirus disease 2019 (COVID-19) outbreak in China: summary of a report of 72314 cases from the Chinese Center for Disease Control and Prevention. [In press]

4. Lu H (2020) Drug treatment options for the 2019newcoronavirus (2019-nCoV). Biosci Trends. 14: 69-71.

5. https: //www.cdc.gov/coronavirus/2019-ncov/hcp/therapeuticoptions.html\#r8

6. Yu F, Du L, Ojcius DM, Pan C, Jiang S (2020) Measures for diagnosing and treating infections by a novel coronavirus responsible for a pneumonia outbreak originating in Wuhan, China. Microbes Infect. 22: 74-79.

7. Cunningham AC, Goh HP, Koh D (2020) Treatment of COVID19: old tricks for new challenges. Critical Care. 24: 91.

8. Dong L, Hu S, Gao J (2020) Discovering drugs to treat coronavirus disease 2019 (COVID-19). Drug Discov Ther. 14: 58-60.

9. Mahase E (2020) Covid-19: What treatments are being investigated? BMJ. 368: $\mathrm{m} 1252$.

10. Kupferschmidt K, Cohen J (2020) Race to find COVID-19 treatments accelerates. Science. 367: 1412-1413.
11. Lim J, Jeon S, Shin HY, Kim MJ, Seong YM, Lee WJ, et al. (2020) Case of the index patient who caused tertiary transmission of COVID-19 infection in Korea: The application of lopinavir/ ritonavir for the treatment of COVID-19 infected pneumonia monitored by quantitative RT-PCR. J Korean Med Sci. 35: e79.

12. Cvetkovic RS, Goa KL (2003) Lopinavir/ritonavir: a review of its use in the management of HIV infection. Drugs. 63: 769-802.

13. Arabi YM, Asiri AY, Assiri AM, Aziz Jokhdar HA, Alothman A, et al. (2020) Treatment of Middle East respiratory syndrome with a combination of lopinavir/ritonavir and interferon- $\beta 1 b$ (MIRACLE trial): statistical analysis plan for a recursive two-stage group sequential randomized controlled trial. Trials. 21: 8.

14. Chu CM, Cheng VC, Hung IF, Wong MM, Chan KH, Chan KS, et al. (2004) Role of lopinavir/ritonavir in the treatment of SARS: initial virological and clinical findings. Thorax. 59: 252-256.

15. Cao B, Wang Y, Wen D, Liu W, Wang J, et al. (2020) A Trial of Lopinavir-Ritonavir in Adults Hospitalized with Severe Covid-19. N Engl J Med. 382: 1787-1799

16. Sheahan TP, Sims AC, Leist SR, Schäfer A, Won J, et al. (2020) Comparative therapeutic efficacy of remdesivir and combination lopinavir, ritonavir, and interferon beta against MERS-CoV. Nat Commun. 11: 222

17. Guo Y, Cao Q, Hong Z, Schäfer A, John W, et al. (2020) The origin, transmission and clinical therapies on coronavirus disease 2019 (COVID-19) outbreak- an update on the status. Military Med Res. 7: 11 .

18. Zhang L. Liu Y (2020) Potential Interventions for Novel Coronavirus in China: A systematic review. J Med Virol. 92: 479-490.

19. Sheahan TP, Sims AC, Graham RL, Vineet DM, Lisa EG, et al. (2017) Broad-spectrum antiviral GS-5734 inhibits both epidemic and zoonotic coronaviruses. Sci Transl Med. 9: 396.

20. Wang M, Cao R, Zhang L, Yang X, Liu J, et al. (2020) Remdesivir and chloroquine effectively inhibit the recently emerged novel coronavirus (2019-nCoV) in vitro. Cell Res. 30: 269-271.

21. Holshue $\mathrm{ML}$, DeBolt $\mathrm{C}$, Lindquist $\mathrm{S}$, Kathy $\mathrm{HL}$, John $\mathrm{W}$, et al. (2020) First Case of 2019 Novel Coronavirus in the United States. N Engl J Med; 382: 929-936.

22. Gordon CJ, Tchesnokov EP, Feng JY, Porter DP, Gotte M (2020) The antiviral compound remdesivir potently inhibits RNAdependent RNA polymerase from Middle East respiratory syndrome coronavirus. J Biol Chem.

23. https: //www.livescience.com/coronavirus-covid-19treatments.html. Accessed on April 5, 2020.

24. https: //www.hospimedica.com/coronavirus/articles/ 294781247/fujifilms-antiviral-becomes-first-approved-drug-totreat-coronavirus-in-china.html. Accessed on April 5, 2020.

25. Chen C, Huang J, Cheng Z, Wu J, Chen S, et al. Favipiravir versus Arbidol for covid-19: a randomized clinical trial. medRxiv 2020.

26. Gao J, Tian Z, Yang X (2020) Breakthrough: Chloroquine phosphate has shown apparent efficacy in treatment of COVID-19 associated pneumonia in clinical studies. Biosci Trends. 14: 72-73.

27. Colson P, Rolain JM, Lagier JC, Brouqui P, Raoult D (2020) Chloroquine and hydroxychloroquine as available weapons to fight COVID-19. Int J Antimicrob Agents. In Press. 
28. Vincent MJ, Bergeron E, Benjannet S, Erickson BR, Rollin PE, et al. (2005) Chloroquine is a potent inhibitor of SARS coronavirus infection and spread. Virol J. 2: 69.

29. Savarino A, Di Trani L, Donatelli I, Cauda R, Cassone A (2006) New insights into the antiviral effects of chloroquine. Lancet Infect. Dis. 6: 67-69.

30. Yan Y, Zou Z, Sun Y, Li X, Xu KF, et al. (2013) Anti-malaria drug chloroquine is highly effective in treating avian influenza A H5N1 virus infection in an animal model. Cell Res. 23: 300-302.

31. Liu J, Cao R, Xu M, Xi W, Huanyu Z, et al. (2020) Hydroxychloroquine, a less toxic derivative of chloroquine, is effective in inhibiting SARS-CoV-2 infection in vitro. Cell Discov. 6: 16.

32. Gautret $P$, Lagier JC, Parola P, Meddeb L, Mailhe M, et al. (2020) Hydroxychloroquine and azithromycin as a treatment of covid-19: results of an open-label non-randomized clinical trial. Int J Antimicrob Agents. 105949.

33. https: //www.cdc.gov/coronavirus/2019-ncov/hcp/therapeuticoptions.html\#r8 Accessed on April 6, 2020.

34. https: //www.who.int/docs/defaultsource/coronaviruse/clinicalmanagement-of-novel-cov.pdf

35. Jin Y, Cai L, Cheng Z, Cheng H, Deng T, et al. (2020) A rapid advice guideline for the diagnosis and treatment of 2019 novel coronavirus (2019-nCoV) infected pneumonia (standard version). Military Med Res. 7: 4.

36. Russell CD, Millar JE, Baillie JK (2020) Clinical evidence does not support corticosteroid treatment for 2019-nCoV lung injury. Lancet. 395: 473-475.

37. Richardson P, Griffin I, Tucker C, Dan S, Olly O, et al. (2020) Baricitinib as potential treatment for 2019-nCoV acute respiratory disease. Lancet. 395: e30-31.

38. https:

//www.roche.com/media/releases/medcor-2020-03-19.htm

39. Hoffmann $M$, Kleine-Weber $H$, Krüger $N$, Müller $M$, Drosten $C$, et al. (2020) The novel coronavirus 2019 (2019-nCoV) uses the SARS-coronavirus receptor 2 ACE2 and the cellular protease TMPRSS2 for entry into target cells. Preprint. bioRxiv.
40. Zhou P, Yang X, Wang X, Ben H, Lei Z, et al. (2020) A pneumonia outbreak associated with a new coronavirus of probable bat origin. Nature. 579: 270-273.

41. Fang L, Karakiulakis G, Roth M (2020) Are patients with hypertension and diabetes mellitus at increased risk for COVID-19 infection? Lancet Respir Med.

42. Li G, Hu R, Zhang $X$ (2020) Antihypertensive treatment with ACEI/ARB of patients with COVID-19 complicated by hypertension. Hypertens Res. 43: 588-590.

43. https: //www.technologynetworks.com/drug-discovery/news/ phase-2-clinical-trial-of-apn01-for-treatment-of-covid-19inititated-332897. Accessed on April 6, 2020.

44. Day M (2020) Covid-19: ibuprofen should not be used for managing symptoms, say doctors and scientists. BMJ. 368: m1086.

45. Shen C, Wang Z, Zhao F, Yang Y, Li J, et al. (2020) Treatment of 5 Critically III Patients with COVID-19 with Convalescent Plasma. JAMA. 323: 1582-1589

46. Duan K, Liu B, Li C, Zhang H, Yu T (2020) Effectiveness of convalescent plasma therapy in severe COVID-19 patients..

47. Kima E, Erdosb G, Huanga S, Kennistona TW, Balmertb SC, et al. (2020) Microneedle array delivered recombinant coronavirus vaccines: Immunogenicity and rapid translational development. EBioMedicine. 55: 102743

48. Le TT, Andreadakis Z, Kumar A, Román RG, et al. (2020) The COVID-19 vaccine development landscape. Nat Rev Drug Discov. 19: 305-306.

49. Caly L, Druce, J D, Catton M G, Jans D A, Wagstaff, KM (2020) The FDA approved Drug Ivermectin inhibits the replication of SARS-CoV-2 in vitro. Antivir Res. 178.

50. Sheahan TP, Sims AC, Zhou S, Graham RL, Pruijssers AJ, et al. (2020) An orally bioavailable broad-spectrum antiviral inhibits SARS-CoV-2 in human airway epithelial cell cultures and multiple coronaviruses in mice. Sci Transl Med. 12. 